\title{
The vital need for Allergy Training: removing the doubts
}

\author{
See linked article by Ellis et al. on pg 19
}

\section{Nikolaos G Papadopoulos', *Savvas Savvatianos²}

1 Associate Professor and Head, Allergy Dept., 2nd Pediatric Clinic, University of Athens, Athens, Greece

2 Consultant and Senior Fellow, Allergy Dept., 2nd Pediatric Clinic, University of Athens, Athens, Greece

*Correspondence: Dr Savvas Savvatianos, Allergy Dept., 2nd Pediatric Clinic, University of Athens, 1 Thivon \& Livadias str., Athens 115 27, Greece

Tel: +30 (694) 4732750 Fax: +30 (210) 7714626

E-mail: ss@allergy.gr

Allergic disorders are probably the most common chronic diseases worldwide. While variations in reported prevalence across different countries exist, depending on geographical particularities and methodological heterogeneity between studies, it is universally demonstrated that the number of allergic patients has risen profoundly over the second half of the last century, posing significant morbidity, impaired quality of life and financial burden on healthcare systems in westernised countries. In the UK, which is among the countries with the highest incidence worldwide,' it has recently been estimated that about one-third of the entire population is affected by some type of allergic disease at some point in their lives. ${ }^{2}$ Although the demands for allergy services are burgeoning, only a small number of allergy specialists and dedicated allergy clinics are generally available. ${ }^{3}$ Within the UK National Health Service (NHS), the responsibility for diagnosis and management of the vast majority of these allergic patients largely falls to primary care services. The quality of allergy training and adequacy of general practitioners (GPs) in meeting this role is therefore critical.

In two consecutive nationwide surveys of UK GPs in 2002 and 2009, less than half of the responders reported having had any type of allergy training, most of which was as undergraduate medical students. ${ }^{45}$ Quality of training was rated low, and only a minority of GPs reported being confident in their allergy knowledge. This was also the case in their ability to perform essential diagnostic procedures (such as skin prick testing), or competence in dealing with systemic manifestations of allergy. Overall, these national surveys of primary care providers reinforced the prevailing view that allergy care provision is not yet optimal in the UK, due to both limited access to specialised care as well as significant lack of specific training of the actual allergy service providers. ${ }^{3,6}$

In this issue of the $P C R J$, Ellis and colleagues attempt to take the analysis a step further by assessing, for the first time, the view of head officers directly in charge of GP training. The authors conducted an internet-based, cross-sectional nationwide survey of General Practice Specialty Training (GPST) programme directors, enquiring about the quality of allergy training as part of GPST programmes, as well as the perceived needs for improvement of GP education in allergy. The findings are of particular interest, as they essentially confirm the educational gaps highlighted by the two previous GP surveys. ${ }^{4,5}$ According to the directors' feedback, no specific training is being offered to GP trainees in as much as one-third of GPST programmes. The percentage is likely to be even higher: considering that directors representing $40 \%$ of programmes did not respond to the survey, it is reasonable to expect that the rate of unfavourable answers among these non-responders would be higher.

Moreover, even when allergy training is reported to be delivered, the perceived quality of educational schemes appears to vary with respect to different types of allergy. Specifically, diagnosis and management of organ-based allergic disorders - such as allergic rhinitis and asthma - were considered adequately covered by most respondents; in contrast, GPST directors did not feel as confident about guidance on diseases with systemic manifestations, especially food allergy. In essence, similar findings of the earlier GP studies ${ }^{4}$ are now corroborated, suggesting validity of these results.?

The lack of confidence of both GP trainers and trainees with regard to the provision of food allergy training is of particular concern. Food allergy is on the rise in most westernised countries, emerging as a second wave of the allergy epidemic. ${ }^{8}$ While the prevalence of respiratory allergy appears to have probably reached a plateau, and experience in managing it has developed over the years, the frequency and severity of food allergy is apparently increasing, primarily affecting children. ${ }^{9,10} \mathrm{~A}$ similar trend is evident in the UK, with the frequency of hospital admissions for food allergy having increased 5-fold in 15 years. ${ }^{10}$ With a shortage of allergy specialists and inadequately trained GPs, the NHS may face substantial problems dealing with this food allergy epidemic. The implications are obvious, both in terms of morbidity and healthcare cost increases. ${ }^{11}$

Having highlighted the educational needs of UK GPs, it should be noted that, with few exceptions, similar unmet needs are recognised all over Europe, as well as in the USA. ${ }^{12}$ One exception is Finland, with its National Allergy Program which includes standardised approaches and systematic educational efforts. ${ }^{13}$ Consequently, several European bodies are currently focusing their efforts in either standardising, or lobbying for, improved allergy education in both specialist and primary care. The Allergy Section of the European Union of Medical Specialists (UEMS), in collaboration with the European Academy of Allergy and Clinical Immunology (EAACI), has prepared an 'Allergy Blueprint', in which the minimum training requirements for allergy care are described; the respective roles of specialist and GP are also touched upon..$^{14} \mathrm{~A}$ position paper of the European Federation of Allergy and Airway Diseases Patient Associations (EFA), supported by EAACI and UEMS, requests endorsement of the European Commission and Parliament for increasing the quality and harmonising education of specialists and primary care physicians in the field of allergy (Papadopoulos NG, personal communication). EAACI has recently established a Primary Care Interest Group to optimise interactions 
between specialists and primary care physicians, to assist harmonisation, and to design and deploy relevant educational tools (see www.eaaci.net).

However, the impact of allergies has only recently been recognised at the political level in Europe, mostly in relation to respiratory allergies. ${ }^{15}$ This is an important step, but it lags behind the observed epidemiological trends with increases in systemic disease entities such as food allergy. In all, there is little doubt that recognition and prioritisation of allergy education in primary care is probably the only way to improve patient outcomes and to prevent devastating consequences in public health.

Conflicts of interest The authors declare that they have no conflicts of interest in relation to this article.

Commissioned article; not externally peer-reviewed; accepted 8th February 2013; online 21st February 2013

(C) 2013 Primary Care Respiratory Society UK. All rights reserved

http://dx.doi.org/10.4104/pcrj.2013.00021

Prim Care Respir J 2013; 22(1): 5-6

\section{References}

1. Worldwide variation in prevalence of symptoms of asthma, allergic rhinoconjunctivitis, and atopic eczema: ISAAC. The International Study of Asthma and Allergies in Childhood (ISAAC) Steering Committee. Lancet 1998;351(9111): 1225-32. http://dx.doi.org/10.1016/S0140-6736(97)07302-9

2. Anandan C, Gupta R, Simpson CR, Fischbacher C, Sheikh A. Epidemiology and disease burden from allergic disease in Scotland: analyses of national databases. J R Soc Med 2009;102(10):431-42. http://dx.doi.org/10.1258/jrsm.2009.090027

3. Royal College of Physicians and Royal College of Pathologists Working Party. Allergy services: still not meeting the unmet need. 2010 http://bookshop.rcplondon.ac.uk/contents/pub317-44f79458-267d-4006-af053f0e468e22c5.pdf (accessed February 2013).
4. Levy ML, Price D, Zheng X, Simpson C, Hannaford P, Sheikh A. Inadequacies in UK primary care allergy services: national survey of current provisions and perceptions of need. Clin Exp Allergy 2004;34(4):518-19. http://dx.doi.org/10.1111/j.13652222.2004.1945.x

5. Hazeldine $M$, Worth $A$, Levy ML, Sheikh A. Follow-up survey of genera practitioners' perceptions of UK allergy services. Prim Care Respir J 2010;19(1):846. http://dx.doi.org/10.4104/pcri.2010.00002

6. Ewan PW, Durham SR. NHS allergy services in the UK: proposals to improve allergy care. Clin Med 2002;2(2):122-27.

7. Ellis J, Rafi I, Smith $\mathrm{H}$, Sheikh A. Identifying current training provision and future training needs in allergy available for UK general practice trainees: national crosssectional survey of General Practitioner Specialist Training programme directors. Prim Care Respir J 2013;22(1):19-22 http://dx.doi.org/10.4104/pcrj.2012.00087

8. Prescott $\mathrm{S}$, Allen KJ. Food allergy: riding the second wave of the allergy epidemic Pediatr Allergy Immunol 2011;22(2):155-60. http://dx.doi.org/10.1111/j.13993038.2011.01145.x

9. Anderson HR, Gupta R, Strachan DP, Limb ES. 50 years of asthma: UK trends from 1955 to 2004. Thorax 2007;62(1):85-90. http://dx.doi.org/10.1136/ thx.2006.066407

10. Gupta R, Sheikh A, Strachan DP, Anderson HR. Time trends in allergic disorders in the UK. Thorax 2007;62(1):91-6. http://dx.doi.org/10.1136/thx.2004.038844

11. Fox M, Mugford M, Voordouw J, et al. Health sector costs of self-reported food allergy in Europe: a patient-based cost of illness study. Eur J Public Health 2013 (in press). http://dx.doi.org/10.1093/eurpub/ckt010

12. Gupta RS, Springston EE, Kim JS, et al. Food allergy knowledge, attitudes, and beliefs of primary care physicians. Pediatrics 2010;125(1):126-32. http://dx.doi.org/ 10.1542/peds.2009-1116

13. Haahtela T, von Hertzen L, Makela M, Hannuksela M. Finnish Allergy Programme 2008-2018--time to act and change the course. Allergy 2008;63(6):634-45

14. de Monchy JG, Demoly P, Akdis CA, et al. Allergology in Europe, the blueprint. Allergy 2013 (in press).

15. Samolinski B, Fronczak A, Wlodarczyk A, Bousquet J. Council of the European Union conclusions on chronic respiratory diseases in children. Lancet 2012; 379(9822):e45-46. http://dx.doi.org/10.1016/S0140-6736(12)60514-5

\section{Is education at the crossroads?}

\section{See linked articles by Ulrik et al. on pg 23 and Patel et al.}

on pg 29

\section{*Ron Tomlins ${ }^{1}$}

1 Adjunct Associate Professor, Discipline of General Practice, Western Clinical School, University of Sydney, Sydney, Australia; Chair, COPD Expert Reference Group, Improvement Foundation of Australia; Treasurer, IPCRG

*Correspondence: Professor Ron Tomlins, PO Box 436,

Cherrybrook, NSW 2126, Australia

Tel: +61412042007 Fax: +61294840073

E-mail: ron_tomlins@optusnet.com.au

Continuing education is a challenge for primary care physicians. ${ }^{1-3}$ The changing emphasis on long-term conditions, the escalating cost of health care delivery, and the impact of new knowledge, new technologies and new treatments, all clash with daily pressures to deliver the highest possible quality of care to our patients. In this issue of the $P C R J$, two papers explore models of delivery of education to primary care physicians in general practice in Australia and Denmark. ${ }^{4,5}$

The Australian study ${ }^{4}$ reports on a study to translate the methodology of Physician Asthma Care Education (PACE), developed by Professor Noreen Clark in Michigan, USA, with adaptations to Australia. PACE teaches clinicians about current best clinical practice in asthma, communicating more effectively with patients, and how to support patients' management efforts. An interactive seminar lasting for five hours over two sessions with trusted knowledge experts, video resources, case studies and advice on access to remuneration formed the educational intervention. The study was funded by the Australian Government, at a cost of AU\$2,000 per practitioner trained.

The Danish study ${ }^{5}$ focused on COPD education delivered in the general practitioner's own practice. The principal intervention was a 3hour teaching session with a respiratory specialist, supported by up to five additional visits from a representative of the sponsoring pharmaceutical company focusing on coding of patients, spirometry and device technique. There are some questions about the identification of patients with COPD based solely on prescribing records, but as the purpose of the study was to demonstrate a change 